\title{
Introduction of Inactivated Polio Vaccine and Specific Determinants of Vaccine Hesitancy
}

\author{
Maduka Donatus Ughasoro ${ }^{1 *}$, Beckie Nnenna Tagbo², Dorothy Omono Esangbedo ${ }^{3}$ \\ ${ }^{1}$ Department of Paediatrics, University of Nigeria Enugu Campus, Enugu, Nigeria \\ ${ }^{2}$ Institute of Child Health/Department of Paediatrics, University of Nigeria Teaching Hospital, Enugu, Nigeria \\ ${ }^{3}$ Division of Paediatrics, Providence Hospital, Ikoyi, Lagos, Nigeria \\ Email: ${ }^{*}$ kakatitis@yahoo.co.uk
}

Received 30 December 2014; accepted 16 January 2015; published 20 January 2015

Copyright (C) 2015 by authors and Scientific Research Publishing Inc.

This work is licensed under the Creative Commons Attribution International License (CC BY).

http://creativecommons.org/licenses/by/4.0/

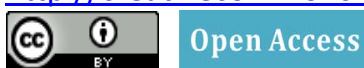

\begin{abstract}
Background: Introduction of inactivated polio vaccine is imminent and may encounter the challenges that face new vaccines especially vaccine hesitancy. The study evaluated factors that may contribute to hesitancy towards IPV. Methods: Questionnaire adapted from the model developed by the Strategic Advisory Group of Experts Working Group (SAGE WG) was used to assess the factors among 408 parents. The evaluation was under the 3 Cs: Confidence, Complacency and Convenience. Questions were scored on Likert 4-unit-scale system. The data were analyzed using SPSS and, multivariate analysis was used to further test individual significant variables. Results: Overall, Complacency (2.29) and Convenience (2.11) domains were more pro-vaccine hesitant, than Confidence (1.83) domain. However, none was significantly associated with likelihood of a parent's hesitancy towards IPV vaccination. But certain individual questions: competence of vaccinators ( $p$ $=0.04)$, confidence that their child will not to be infected with poliomyelitis even when not vaccinated $(p=0.03)$ and, willingness to vaccinate with IPV when OPV is still in use $(p=0.01)$ were significantly associated with vaccine hesitancy. Conclusions: None of the factors can individually influence acceptance of IPV. However, competence of vaccinators, parental belief and availability of close alternative influenced parental decision to vaccinate.
\end{abstract}

\section{Keywords}

Vaccine Hesitancy, Parental Decision, Nigeria

\footnotetext{
${ }^{*}$ Corresponding author.
}

How to cite this paper: Ughasoro, M.D., Tagbo, B.N. and Esangbedo, D.O. (2015) Introduction of Inactivated Polio Vaccine and Specific Determinants of Vaccine Hesitancy. World Journal of Vaccines, 5, 8-18. 


\section{Introduction}

There is currently, a strong advocacy by the World Health Organization (WHO) for countries using only oral polio vaccine (OPV) to introduce inactivated polio vaccine (IPV), in different combinations with OPV. The timing of this strategy is critical, since many low-income countries have introduced several new vaccines to their basic six vaccines of the Expanded Programme on Immunization. Haemophilus Influenzae Type B vaccine (Hib) was introduced into the Nigerian national immunization programme, 33 years after Hib vaccine introduction [1] [2]. Similarly, other vaccines such as polyvalent pneumococcal conjugated vaccine (PCV) and Rotavirus vaccine (RV) have been introduced in many countries [3] [4]. These vaccines have not been included in the publicly funded National Immunization Programme in Nigeria, so parents/caregivers who want their children to receive the vaccines have to pay out-of pocket. Recent debates renew the issues in the ease of administration of IPV as compared to OPV and the cost-effectiveness and efficacy of IPV as replacement of or in conjunction with the routinely used OPV [5].

Vaccines in general, whether already in use or newly introduced are faced with the challenge of parental acceptability. The factors that influence the decision by parents or caregivers to allow their children to receive vaccines are enshrouded in complex direct and indirect factors. The concept of "vaccine hesitancy" deals with decision-making and determinants of accepting vaccine. According to the model developed by the Strategic Advisory Group of Experts Working Group (SAGE WG) for vaccine hesitancy assessment: confidence (level of trust on the vaccine and the provider), complacency (poor perception of the need and value of vaccine), and convenience (issue of access both on mode and place of delivery of vaccine) are the core domains [6] [7]. A respondent is said to be vaccine hesitant if he/she was found to lack confidence on vaccination, complacency towards vaccination and/or found mode of administering vaccines inconvenient. A parent being vaccine hesitant does not mean absolute refusal of vaccine, some may accept vaccines but still remain concerned about the vaccines they have received. Therefore, there are vaccine hesitant parents even among parents that have had their children vaccinated or that brought their children for immunization. This raised the question on the appropriate population that has to provide their preferences on health related issues such that decision can be based on it [8]. Some theoretically argue in favor of evaluating the general population [9] as the suitable population. Their reason being that the impact of any new health product or program depend on all the subjects that will benefit from it. However, majority are in favor of using patients or subjects currently experiencing the product or program, since they are in the better position to evaluate the product. The argument is that those parents that present for immunization have a good understanding of vaccination as there is no health worker asymmetry of information.

Vaccine hesitant parents are heterogenous, therefore, evaluating determinants of vaccine hesitancy refers firstly, to vaccines already in use, which deals with parental experiences with the vaccine and the impact of low prevalence of that particular disease prior to the use of the vaccine; and secondly, the evaluation of a new vaccine which deals with the compelling factor of high disease burden which may cease to exist after immunization. The case is different with IPV which is to replace OPV that has been in use for a prolonged period and has reduced the prevalence of poliomyelitis [10] [11]. Another factor is that IPV is delivered as an injection with the associated injection pain and complications of injection. All these factors make IPV more subjective to parent vaccine hesitancy.

Previous studies have surveyed vaccine safety [12] [13] and parental perceptions on vaccines [14] [15]. There are no published studies regarding vaccine hesitancy among parents/caregivers to the best of our literature search as at the time of this study. One qualitative study in USA had reported poor awareness about vaccine as a barrier to parental reception of vaccine, but this just tested one sub-set in one of the components of the contextual framework for assessing vaccine hesitancy [16]. However, no study has reported any outcomes regarding the 3 Cs: confidence, complacency, and convenience. This study aimed to assess vaccine hesitancy, using IPV as the case study of the three components of the contextual framework for assessment of vaccine hesitancy.

\section{Methods}

\subsection{Respondents' Recruitment and Data Collection}

Participants in the study were parents that brought their children for immunization. Random systematic sampling based on the daily immunization attendance register was used to select parents to be interviewed. Two sites: University of Nigeria Teaching Hospital, Enugu and Federal Medical Centre Umuahia, were randomly chosen 
for the study among the five hospitals selected due to the large population of children that attend immunization clinic and the wide catchment area from where parents bring their children for vaccination. The same protocol and questionnaire were used for the study in the two sites. Parents, who were willing to participate in the study, were requested to give their written consent before administering the questionnaire. The targeted minimum sample size was to recruit 369 respondents according to $81.3 \%$ participation reported by Williams et al. [17] in their study of acceptability of vaccine by vaccine-hesitant parents.

\subsection{Survey Instrument Development}

The instrument used for data collection was adapted from the model developed by the Strategic Advisory Group of Experts Working Group (SAGE WG) for the assessment of the determinants of vaccine hesitancy. This framework is effective and reliable and is commonly used to identify the main determinants of vaccine hesitancy. The SAGE WG framework serves as a standard because it considers the common psychosocial factors that are related to vaccine hesitancy. According to SAGE WG framework, vaccine hesitancy can be assessed under three main arms: a) contextual influences; b) individual/social group influences and c) vaccine and vaccination-specific issues (Figure 1). Some aspect of these arms especially the vaccine and vaccination-specific arm can be evaluated using three domains: confidence, complacency and convenience.

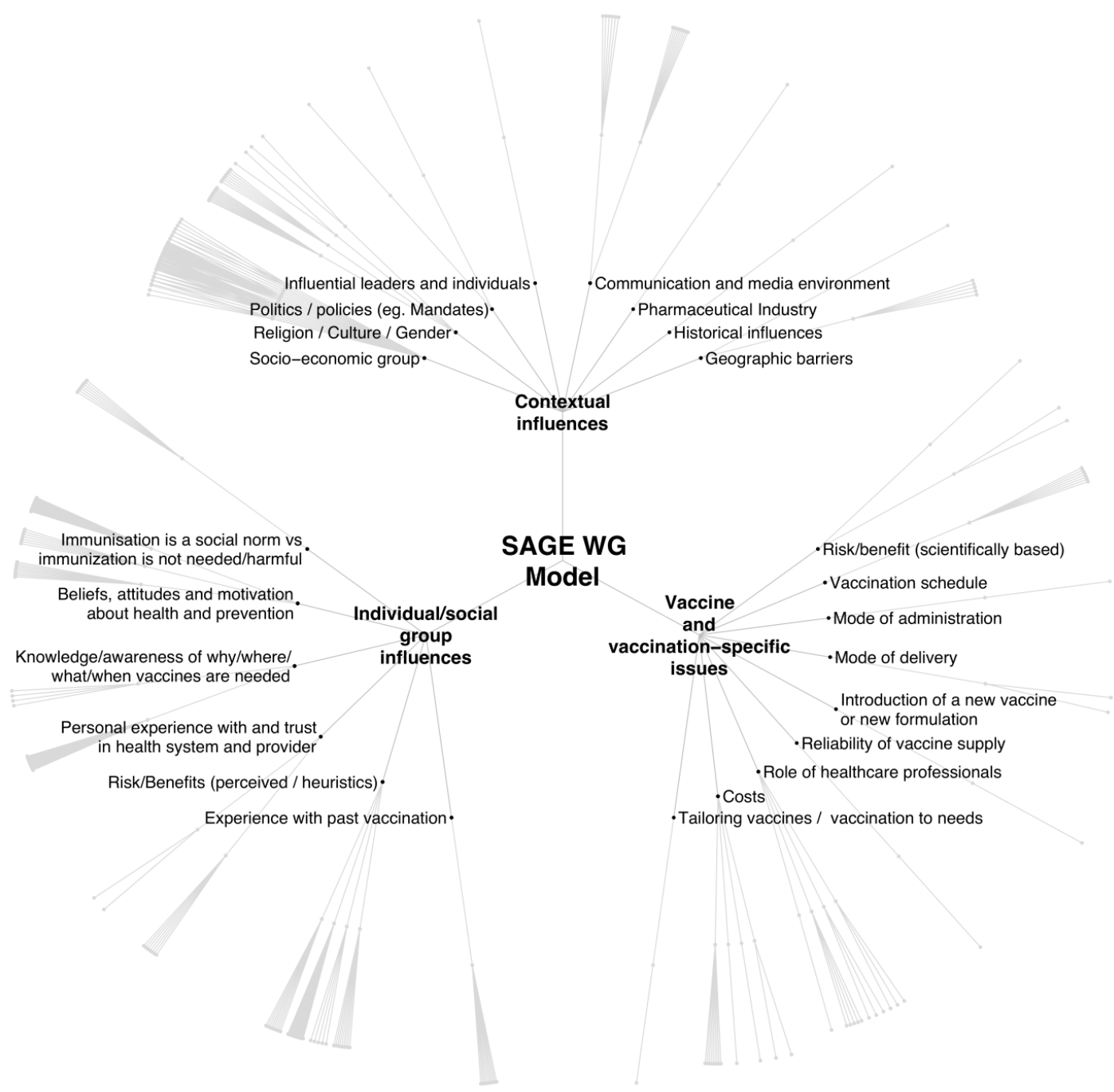

Figure 1. Overview of SAGE Working Group (WG) "Model of determinants of Vaccine Hesitancy" (source: Larson et al. Vaccine 2014; 32, 2150-9). 
Vaccination confidence deals with issues concerning trust of the efficacy and safety of vaccine and the system that see to its delivery. This includes the competence and reliability of the vaccinator as well as the motivating factor that influenced the policy decisions on different vaccines. A major factor of vaccine complacency is the perception of reduced threat/risk due to low prevalence of vaccine preventable diseases in a particular region with no obvious need for preventive actions. Other factors are the poor perception of disease threat (severity and transmission), the poor appreciation of efficacy of vaccine (adverse events/safety profiles and/or effectiveness of the vaccine) and poor knowledge of vaccines. Successful immunization program has vaccine complacency and vaccine hesitancy as some negative externalities since parents consider the risks/side effects of vaccines higher when compared against the risk of contracting the diseases especially when prevalence is no longer high as a result of successful immunization program. Vaccination convenience is the real and perceived quality of the healthcare service, the extent to which vaccination exercises are delivered in time, place and mode that is viewed as appealing, convenient, affordable, and comfortable. These three concepts together influence the decision to receive vaccine.

Each participant's demographic characteristics were collected: age, educational status, occupation, household size and questions related to their index child's immunization status. A total of 12 items were developed for the 3 domains and each item had questions on a four-point Likert scale (Figure 2).

The questionnaire was pre-tested and gray areas were revised before its implementation in the study. Parents were educated on poliomyelitis disease, OPV and information on IPV during the recruitment because IPV was unknown to many and yet to be widely administered. The information on IPV was read from a standard information sheet to ensure that all the respondents received the same level of knowledge on poliomyelitis disease and IPV. The respondents were informed that IPV is an injectable form of polio vaccine that has some advantages over OPV that include no risk of poliomyelitis virus infection. WHO has recommended that IPV should be combined with OPV to achieve faster eradication of polio and should be administered as two doses of IPV, then two doses of OPV.

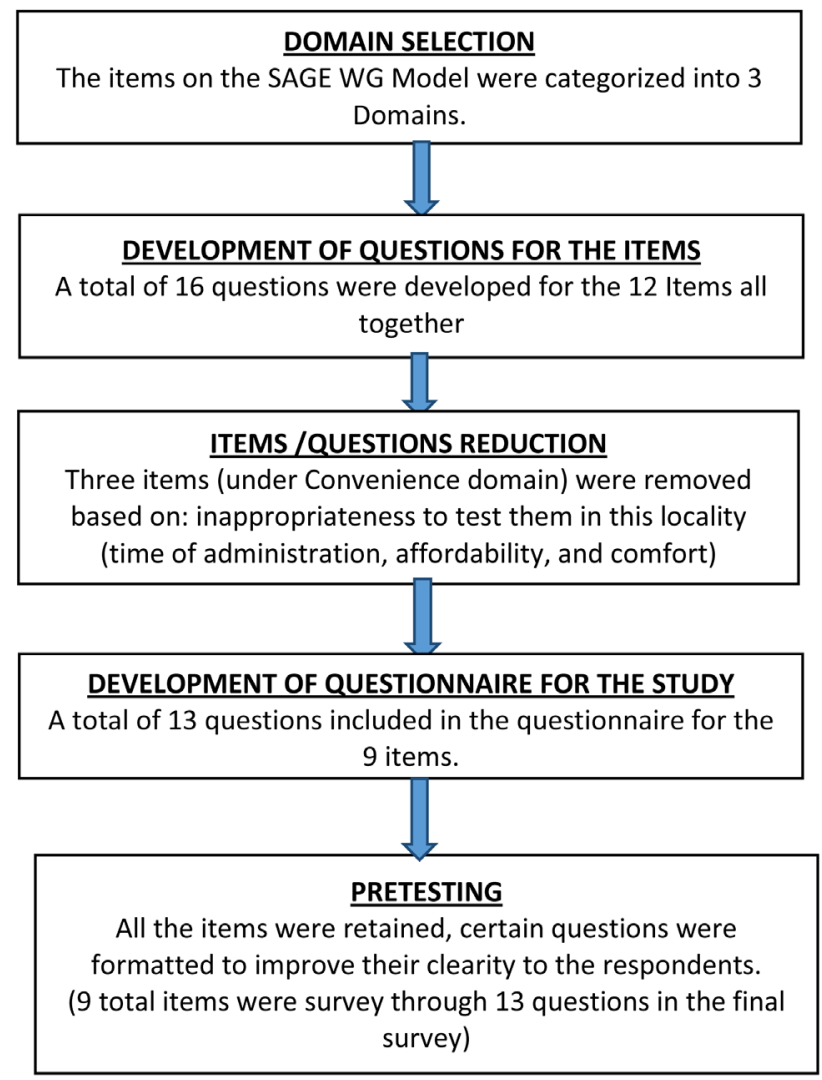

Figure 2. Survey development summary. 
The Medical and Health Research Ethics Committee of UNTH approved the study protocol before the study was commenced.

\subsection{Analysis}

Statistical analysis was done using the Statistical Package for Social Sciences (SPSS) version 20, excluding incomplete data. The level of statistical significant was tested using chi-squared $(\chi)$ or Fisher's exact (if variable is 5 or less).

The Likert-type scale ranged from "strongly agree" to "strongly disagree", and "not at all hesitant" to "very hesitant" with no neutral answer: "not sure” or "don't know" as shown in Table 1. The idea of eliminating neutral answer is to reduce the chances of passive responses. Strong agreement has the score of " 1 " and it is an indication that the variable being tested is very unlikely to encourage vaccine hesitancy, and strong disagreement has score of "4" and a high probability that the event will encourage vaccine hesitancy. The responses to the

Table 1. The domains, sub-domain items and research questions initially developed before further modification for the study.

\begin{tabular}{ccc}
\hline Domain. & Item & Response format \\
\hline $\begin{array}{c}\text { Confidence } \\
\text { Efficacy }\end{array}$ & Do you think that immunization works? & SA/A/D/SD
\end{tabular}

Safety

Will you still immunize you child even if he/she will suffer side effects?

When introduced will you vaccinate your child with IPV?

Do you have any fear about the proposed use of IPV?

Competence of Healthcare provider

Motivating factor for introducing the vaccine.

Overall Score on Confidence

Complacence

Risk of being infected

Side effects

Knowledge of vaccine.

\section{Overall Score on Complacence}

$$
\begin{gathered}
\text { How confident are you that your child will not suffer from Poliomyelitis even if } \\
\text { not immunized? }
\end{gathered}
$$

NAC/NTC/SC/VC

How convinced are you that vaccines can cause adverse event?

How knowledgeable are you on the major content of vaccine?

Do you believe the rumours you heard about vaccines?

VC/SC/NTC/NACV

K/SK/NTK/NAK

$\mathrm{SA} / \mathrm{A} / \mathrm{D} / \mathrm{SD}$

$\mathrm{NAH} / \mathrm{NTH} / \mathrm{SH} / \mathrm{VH}$

$\mathrm{NAH} / \mathrm{NTH} / \mathrm{SH} / \mathrm{VH}$

NAA/NTA/SA/AF

VC/SC/NTC/NAC

$\mathrm{A} / \mathrm{B}$

\section{Convenience}

Time of administration ${ }^{*}$

Place of administration

Will you go to health facility to vaccinate your child with IPV?

Will you agree to your child receiving OPV during house-to-house campaign?

Route

Affordability $^{*}$

Comfortable*

\section{Overall Score on Convenience}

Will you hesitate to go for an injectable vaccine when there is an oral alternative?

Are you comfortable with the number of vaccines in the immunization programme.
How much are you willing to pay to receive IPV?
$\mathrm{SA} / \mathrm{A} / \mathrm{D} / \mathrm{SD}^{* *}$

$\mathrm{SA} / \mathrm{A} / \mathrm{D} / \mathrm{SD}$

$\mathrm{SA} / \mathrm{A} / \mathrm{D} / \mathrm{SD}$

NAH/NTH/SH/VH

NAC/NTC/SC/VC

${ }^{*}$ Items expunged from the final survey. SA/A/D/SD: Strongly Agree $\left(\right.$ to time $\left.{ }^{* *}\right) /$ Agree to time $\left.{ }^{* *}\right) /$ Disagree $\left(\right.$ to time $\left.{ }^{* *}\right) /$ Strongly Disagree $\left({ }^{* *}\right)$. Y/N: Yes/No. NAH/NTH/SH/VH: Not at all hesitant/Not too hesitant/Somewhat hesitant/Very hesitant. NAA/NTA/SA/AF: Not at all afraid/Not too afraid/Somewhat afraid/Very afraid VC/SC/NTC/NAC: Very confident (comfortable/convinced)/somewhat confident (comfortable/convinced)/Not too confident (comfortable/convinced)/Not at all confident (comfortable/convinced). VK/SK/NTK/NAK: Very knowledgeable/somewhat knowledgeable/Not to knowledgeable/Not at all Knowledgeable. 
questions are formatted such that low score of the questions will point towards vaccine acceptability, while a high score will point towards vaccine hesitancy. The final scoring of each domain was the mean score of the individual questions asked under that domain. Both the overall domains scores and the individual questions scores were dichotomized from the four-point scale with a mean value of 2 as a cutoff, with scores $>2$ indicating high vaccine hesitancy.

If an infant has any outstanding vaccines at the time of survey, he/she was grouped as under-immunized. If the infant has outstanding vaccine but was to receive them at later age, he/she was grouped as delayed. If the infant was receiving the vaccines at recommended age, he/she was grouped as up-to-date. If seen at 9 month and has had or about to receive the recommended vaccine for the $9^{\text {th }}$ month, he/she was grouped as fully immunized.

The parents were categorized either as "vaccine hesitant" or "non-vaccine hesitant" with regard to their response to the question: When IPV is introduced will you vaccinate your child with IPV?” Those that responded in positivity are "non-vaccine hesitant" while those that responded in negativity, were grouped as "vaccine hesitant". All the variables whose responses were found to be significantly different $(p \leq 0.05)$ between the two groups in the univariate analysis were entered into the multivariate regression model using the forward stepwise approach. The variables were categorized into binary variables depending on their scores: those that scored 1 or 2 are grouped as "vaccine acceptance" while scores of 3 or 4 are grouped as "vaccine hesitant". The multivariate regression analysis was used to re-evaluate the final domain checking for confounding and model fit. The socio-economic status was determined using Oyedeji's classification method [18] based on both parents education and occupations. Social class I \& II are regarded as high class, while III, IV \& V classified as low class. Extent of completeness of the immunization status of the index child was also analyzed.

The Descriptive Domains were developed from the SAGE WG model. Sub-domain items and their research questions were developed to suit Nigerian context.

\section{Results}

Out of 426 respondents that were approached for study and 6 respondents declined to participate. Of 426 eligible respondents, 420 were interviewed given a cooperation rate of $98.6 \%$. The 420 respondents that gave their consent to participate in the survey, 12 questionnaires were excluded from analysis, the reason being incomplete data from caregivers/parents that left mid interview and did not return to complete the survey (Figure 3) [19].

408 parents completed the survey in both sites and their socio-demographic characteristics are represented in Table 2. Most (403, 98.8\%) of the respondents were female. Most (401, 98.3\%) had at least secondary school education and 341 (83.7\%) resides in urban area. Their compliance with immunization was very positive (95.1\% was either about to receive the last dose to complete their child recommended vaccines or regular with receiving the vaccines).

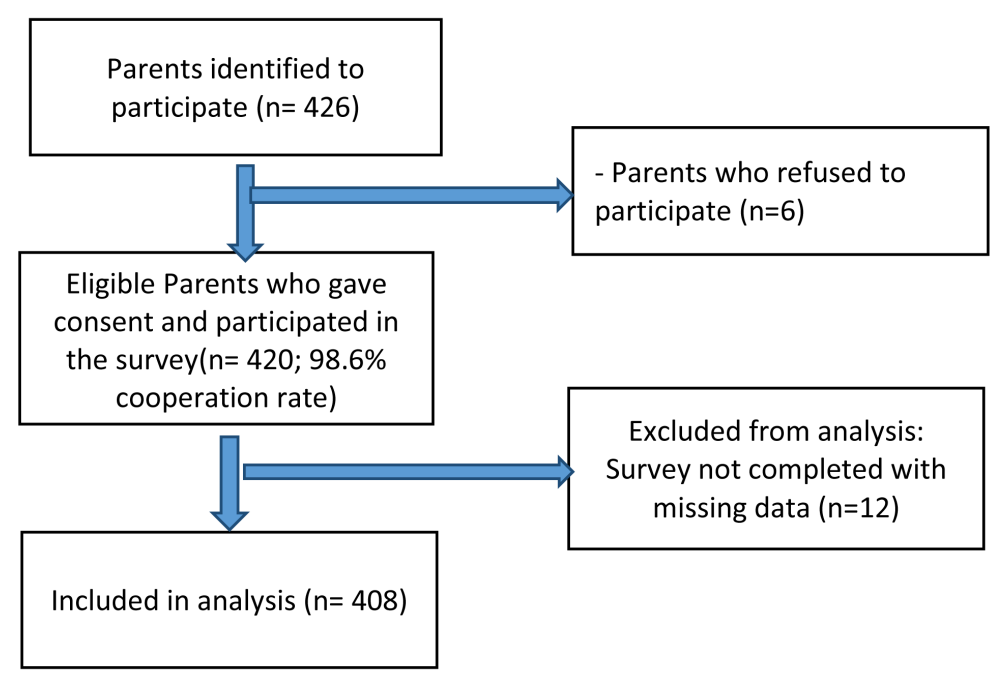

Figure 3. Sample selection framework. (Source: Tagbo et al. Vaccine 2014 doi:10.1016/j.vaccine.2014.08.053). 
Table 2. Characteristics of parents.

\begin{tabular}{|c|c|c|}
\hline Variables & $n=408$ & $\%$ \\
\hline \multicolumn{3}{|l|}{ Parents’ age } \\
\hline$\leq 30$ years old & 196 & 48.0 \\
\hline$>30-\leq 39$ years old & 202 & 49.5 \\
\hline$\geq 40$ years old & 10 & 2.5 \\
\hline \multicolumn{3}{|l|}{ Gender } \\
\hline Female & 403 & 98.8 \\
\hline Male & 5 & 1.2 \\
\hline \multicolumn{3}{|l|}{ Parents' Education } \\
\hline Primary or no formal education & 7 & 1.7 \\
\hline Secondary or higher education & 401 & 98.3 \\
\hline \multicolumn{3}{|l|}{ Socio-economic status } \\
\hline High (I \& II) & 222 & 54.5 \\
\hline Low (III, IV \& V) & 186 & 45.5 \\
\hline \multicolumn{3}{|l|}{ Religion } \\
\hline \multicolumn{3}{|l|}{ Christian } \\
\hline Islam & 405 & 99.3 \\
\hline \multirow[t]{2}{*}{ Traditional } & 3 & 0.7 \\
\hline & 0 & - \\
\hline \multicolumn{3}{|l|}{ Area of Resident } \\
\hline Urban & 341 & 83.7 \\
\hline Rural & 67 & 16.3 \\
\hline \multicolumn{3}{|l|}{ Index child Immunization status } \\
\hline Fully Immunized/up-to-date & 388 & 95.1 \\
\hline Under immunized/Delayed & 20 & 4.9 \\
\hline
\end{tabular}

\section{Parents' Hesitance towards Vaccinating Their Child with IPV (Table 3)}

The overall score for each of the three vaccine hesitancy domains except confidence were pro-vaccine hesitance, although there was statistically significant difference $(p>0.05)$ between the responses of vaccine hesitant parents and non-vaccine hesitant parents. When the itemized questions were analyzed individually, the response to two questions: "How confident are you on the competence of the vaccinators" and "How confident are you that your child will not suffer from poliomyelitis even if not immunized?" revealed statistically significant difference ( $p=0.04$ and 0.03 respectively) in the response. Most of the parents (average score of $3.16 \pm 1.28$ ) were of the opinion that once OPV is still being administered they will prefer OPV to IPV. There was no statistically significant difference between "vaccine hesitant" and "non-vaccine hesitant" parents regarding their willingness to vaccinate their child with IPV. The linear regression analysis indicated that none of the three tested domains had any significant impact on the parent's vaccine hesitant attitude. Nevertheless, their difference in belief on whether their child will suffer poliomyelitis if not vaccinated and the difference in the level of confidence that they have on the competence of the vaccinators were noted to significantly vary ( $p=0.03$ and 0.02 respectively) Table 4.

\section{Discussion}

There was a wide gap between what parents knew about vaccines and what they were willing to do. This has been reported by other studies [20] [21]. Most believed that vaccines can cause adverse events, lack knowledge on vaccine content and were not confident that the vaccinators are competent enough to execute their duties. But 
Table 3. Results of vaccine hesitance scales.

\begin{tabular}{|c|c|c|}
\hline Domains/Items/Questions & Mean score \pm SD & $\begin{array}{c}\text { Correlation with } \\
\text { vaccine Hesitancy }\end{array}$ \\
\hline \multicolumn{3}{|l|}{ Confidence } \\
\hline \multicolumn{3}{|l|}{ Efficacy } \\
\hline (1) Do you think that immunization works? & $1.77 \pm 0.21$ & 0.85 \\
\hline \multicolumn{3}{|l|}{ Safety } \\
\hline (2) Will you still immunize you child even if he/she will suffer side effects? & $1.36 \pm 0.95$ & 0.45 \\
\hline (3) When introduced will you vaccinate your child with IPV? & $1.63 \pm 0.57$ & - \\
\hline (4) Do you have any fear about the proposed use of IPV? & $1.58 \pm 1.09$ & 0.27 \\
\hline \multicolumn{3}{|l|}{ Competence of Healthcare provider } \\
\hline (5) How confident are you on the competence of the vaccinators? & $2.82 \pm 0.91$ & 0.04 \\
\hline \multicolumn{3}{|l|}{$\begin{array}{l}\text { Motivating factor for introducing the vaccine. } \\
\text { (6) Which one is the main reason for introducing IPV: }\end{array}$} \\
\hline $\begin{array}{l}\text { (a) to prevent diseases or } \\
\text { (b) government means to embezzle funds? }\end{array}$ & $\begin{array}{l}\text { A }(97.5 \%) \\
\text { B }(2.5 \%)\end{array}$ & - \\
\hline Overall Score on Confidence & $1.83 \pm 0.75$ & 0.35 \\
\hline \multicolumn{3}{|l|}{ Complacence } \\
\hline \multicolumn{3}{|l|}{ Risk of being infected } \\
\hline $\begin{array}{c}\text { (7) How confident are you that your child will not suffer from Poliomyelitis even if not immunized? } \\
\text { Side effects }\end{array}$ & $3.46 \pm 0.72$ & 0.03 \\
\hline (8) How convinced are you that vaccines can cause adverse event? & $2.64 \pm 1.19$ & 0.50 \\
\hline \multicolumn{3}{|l|}{ Knowledge of vaccine } \\
\hline (9) How knowledgeable are you on the major content of vaccine? & $1.38 \pm 0.19$ & 0.68 \\
\hline (10) Do you believe the rumours you heard about vaccines? & $1.55 \pm 0.27$ & 0.34 \\
\hline Overall Score on Complacence & $2.29 \pm 0.42$ & 0.62 \\
\hline \multicolumn{3}{|l|}{ Convenience } \\
\hline Place of administration & $1.22 \pm 0.96$ & 0.29 \\
\hline (11) Will you go to health facility to vaccinate your child with IPV? & & \\
\hline $\begin{array}{c}\text { (12) Will you agree to your child receiving OPV during house-to-house campaign? } \\
\text { Route }\end{array}$ & $1.96 \pm 0.73$ & 0.43 \\
\hline (13) Will you hesitate to go for an injectable vaccine when there is an oral alternative? & $3.16 \pm 1.28$ & 0.01 \\
\hline Overall Score on Convenience & $2.11 \pm 0.99$ & 0.61 \\
\hline
\end{tabular}

Scoring format for each questions: 1 : Strongly Agree $=1$, Agree $=2$, Disagree $=3$, Strongly Disagree $=4.2 \&$ : Not at all hesitant $=1$, Not too hesitant $=2$, somewhat hesitant $=3$, Very hesitant $=4.4$ : Not at all afraid $=1$, Not too afraid $=2$, somewhat afraid $=3$, Very afraid $=4$. 5 : Very confident $=1$, somewhat confident $=2$, Not too confident $=3$, Not at all confident $=4.7$ : Very confident $=4$, somewhat confident $=3$, Not too confident $=2$, Not at all confident $=1$. 8: Very convinced $=4$, somewhat convinced $=3$, Not too convinced $=2$, Not at all convinced $=1$. 9: Very knowledgeable $=1$, somewhat knowledgeable $=2$, Not too knowledgeable $=3$, Not at all Knowledgeable $=4$. 10: Strongly Agree $=4$, Agree $=3$, Disagree $=2$, Strongly Disagree $=1$. 11 \& 12: Strongly Agree $=1$, Agree $=2$, Disagree $=3$, Strongly Disagree $=4.13:$ Not at all hesitant $=1$, Not too hesitant $=2$, somewhat hesitant $=3$, Very hesitant $=4$.

Table 4. Variables associated with parents’ hesitancy to have their child vaccinated against IPV $(\mathrm{n}=408)$.

\begin{tabular}{|c|c|c|c|}
\hline Independent Variables & $\boldsymbol{\beta}$ & $\boldsymbol{R}^{2}$ & $p$ \\
\hline Will child suffer poliomyelitis if vaccine was not given? (VA \& VH) & 0.24 & 0.73 & 0.02 \\
\hline Do you have confidence on the vaccinators ("VA” or “VH”) & -0.06 & 0.65 & 0.03 \\
\hline To vaccinate IPV when OPV is still being used ("VA" or "VH”) & 0.75 & 0.24 & 0.01 \\
\hline
\end{tabular}

Multivariate analysis, Score of 1 \& 2 = vaccine acceptance (VA); 3 \& 4 = vaccine hesitant (VH).

they were still willing to allow their child to be vaccinated with IPV. This is in keeping with the report that even without adequate vaccine knowledge; most parents will still vaccinate their children [22]. Introduction of IPV shares the contextual influences of both an existing vaccine and an entirely new vaccine, while previous vaccine hesitance studies have been on vaccine hesitancy to already available vaccines. There is a potential of vaccine hesitancy towards IPV when introduced and OPV is still retained in the immunization schedule, especially if the clinical reasons behind introduction of IPV are not adequately disseminated to the people. 
The proportion of parents who were hesitant to vaccinate their children with IPV if OPV is still retained in the immunization schedule was high, but not significant. This means that though parents still prefer OPV, they will reluctantly accept IPV once approved by the ministry of health even if OPV is still retained as an option. Studies have shown that with the right information, and adequate awareness creation and availability of new vaccine, parents vaccinate their child with newly introduced vaccine [23] [24]. Therefore, with adequate information and awareness creation, parents will accept IPV, although the extent of their acceptance will be influenced by other factors such as whether IPV will be included in publicly funded vaccines. It is expected that IPV will come at no cost to the parents since OPV is delivered free of charge. Therefore, the issue of willingness-to-pay for IPV may not exist. The fact that the risk of poliomyelitis has been drastically reduced by prior, prolonged and wide use of OPV, such that most young parents are not conscious of the threat of poliomyelitis. This will further encourage their hesitancy towards the new vaccine. The scenario will be different if the vaccine being considered is entirely new and the first vaccine being introduced for the disease, as with the Ebola virus vaccine that is still on clinical trial prior to introduction in a situation of panic to prevent a global pandemic of the disease. The current reality of the high transmission of Ebola virus and the high mortality rate are compelling influences on virtually all parents to accept the vaccine, without any recourse to the possible side effects, financial cost and multiple vaccines already in the immunization schedule [25]. Another, factor in IPV hesitancy is that injection-associated pain will further contribute to vaccine hesitancy.

Most of the responses given by the parents were pro-vaccine hesitancy, but majority still accepted to vaccinate their children. This highlights the lack of connection between their understanding of various aspect of vaccination and their intended actions. Nonetheless, the fact that all the recruitment of participants in the study took place in immunization clinics indicate that the parents are likely to be pro-vaccine oriented, and may not be representative of the entire community. Normally, parents are given health talk at the immunization centers before administering vaccines. Therefore they are more exposed to the benefits of vaccination, and irrespective of the barriers and challenges, they are relatively empowered to act in a pro-vaccine manner. This may be a possible explanation of why a proportion of parents willing to vaccinate their children with IPV did not change much irrespective of their response to item questions. This further highlights the impact of health education on vaccine acceptance. Relatively equal proportion of the respondents held negative and positive attitudes towards the different aspects of vaccination program. However, majority were strong on their intention to vaccinate their children with IPV. This could be due to the already established parents' disposition to accepting any health related intervention, provided it is presented in a health facility.

The proportion of the parents that believed that their children will not contract poliomyelitis even if not vaccinated was low. It is still worrisome that some parents still harbor such belief. The importance of such belief can be highlighted if the debilitating effect of poliomyelitis is viewed against relatively safe and non-invasiveness of both polio vaccines, OPV or IPV. This cannot be taken to mean that these parents may risk their children suffering from poliomyelitis but may be simply manifestation of psychosocial determinants. There is little report of recent acute flaccid paralysis, at this time of end-game strategies for polio eradication. This kind of disposition is bound to increase the more we approach poliomyelitis elimination in different regions. Efforts should be made to increase public consciousness of poliomyelitis through effective social media at this stage of polio eradication. This will prevent losing the momentum of what has been gained with polio eradication intervention over the years.

The lack of trust on the competence of health care providers involved in immunization program by the parents as reported in this study should be explored further. This contrasts to other studies that reported, that one of the major factors that promotes acceptance of vaccines is healthcare providers' recommendation of the vaccine [19] [26]. This puts a lot of weight on the impact of healthcare provider recommendation of vaccines to parents. But it will be difficult to estimate such impact if parents lack confident on the health care providers involved in the immunization programs. However one factor that has to be clarified is the cadre of health workers that parents trust and which they doubt their competence.

A major limitation of this study was not including a community evaluation to get opinion of those that will utilize immunization services in the future, since the differences between the responses of the parents seen at the immunization facilities and a community study will to a greater extent represent the actual disposition of the entire population. The respondents involved in this study were mainly urban dwellers, fairly educated and mostly Christian, which may not be a good representation of the overall Nigerian population. However, regional or small unit evaluation is very helpful in the development of an intervention that brings indigenous solution rather 
than evaluation at the national or global level. Another limitation is the simple independent application of each of the domains and its item questions which does not represent what is obtainable in real life practice. A discrete choice experimental study, where all the attributes and levels obtained from literature search and interviews are combine in a near real-life practicable scenario with cost component would have been worthwhile.

\section{Conclusion}

In conclusion, the hesitancy of parents about new vaccine is low, in spite of all the barriers and challenges stated. This is good for the successful introduction of any vaccine, though effort should be made to attend to these potential determinants towards hesitancy to vaccinate children by parents. To the best of our knowledge, no vaccine hesitant study has been carried out in Nigeria; therefore this study gave insight into potential factors that can affect immunization program in Nigeria.

\section{Acknowledgements}

We thank all parents that participated in this study.

\section{Contributors' Statement Page}

Tagbo Beckie Nnenna: Beckie Conceptualized and designed the study. She designed the data collection instruments. Ughasoro Maduka Donatus: Maduka collected data, coordinated and supervised data collection and carried out the initial analyses. He drafted the initial manuscript. Esangbedo Dorothy Omono: Dorothy reviewed and revised the manuscript. All authors approved the final manuscript as submitted and agree to be accountable for all aspects of the work.

\section{Abbreviations}

Strategic Advisory Group of Experts Working Group (SAGE WG); UNTH: University of Nigeria Teaching Hospital.

\section{Funding}

None.

\section{Financial Disclosure}

The authors have no financial relationship relevant to this article to disclose.

\section{Potential Conflicts of Interest}

The authors have no conflicts of interest relevant to this article to disclose.

\section{References}

[1] Hajjeh, R.A., Privor-Dumm, L., Edmond, K., O’Loughlin, R.O., Shetty, S., Griffiths, U.K., Bear, A.P., Cohen, A.L., Chandran, A., Schuchat, A., Mulholland, E.K. and Santosham, M. (2010) Supporting New Vaccine Introduction Decisions: Lessons Learned from the Hib Initiative Experience. Vaccine, 28, 7123-7129. http://dx.doi.org/10.1016/j.vaccine.2010.07.028

[2] Haemophilus Influenza Type b Vaccine Support. Gavi the Vaccine Alliance. www.gavi.org/support/nvs/hib/

[3] Abdulkarim, A.A., Ibrahim, R.M., Fawi, A.O., Adebayo, O.A. and Johnson, A.W.B.R. (2011) Vacines and Immunization: The Past, Present and Future in Nigeria. Nigerian Journal of Paediatrics, 38, 186-194. http://dx.doi.org/10.4314/njp.v38i4.72382

[4] PAN Advisory Committee on Immunization (2012) Paediatric Association of Nigria (PAN) Recommendation Routine Immunization Schedule for Nigeria Children. Nigerian Journal of Paediatrics, 39, 152-158.

[5] Ehrenfeld, E., Glass, R.I., Agol, V.I., Chumakov, K., Dowdle, W., John, T.J., Katz, S.L., Miller, M., Breman, J.G., Modlin, J. and Wright, P. (2008) Immunization against Poliomyelitis: Moving Forward. The Lancet, 371, 1385-1387. http://dx.doi.org/10.1016/S0140-6736(08)60597-8 
[6] Report of the SAGE Working Group on Vaccine Hesitancy. www.who.int/immunization/sage/meetings/2014/october/1_report_WORKING_GROUP_vaccine_hesitancy_final.pdf

[7] Larson, H.J., Jarrett, C., Eckersberger, E., Smith, D. and Paterson, P. (2014) Understanding Vaccine Hesitancy around Vaccines and Vaccination from a Global Perspective: A Systematic Review of Published Literature, 2007-2012. Vaccine, 32, 2150-2159.

[8] Ube, P.A., Richardson, J. and Menzel, P. (2000) Societal Value, the Person Trade-Off, and the Dilemma of Whose Values to Measure for Cost-Effectiveness Analysis. Health Econ, 9, 127-126. http://dx.doi.org/10.1002/(SICI)1099-1050(200003)9:2<127::AID-HEC500>3.0.CO;2-Y

[9] O’Brien, B. and Gafni, A. (1996) When Do the "Dollars” Make Sense? Toward a Conceptual Framework for Contigent Valuation Studies in Health Care. Medical Decision Making, 16, 288-299. http://dx.doi.org/10.1177/0272989X9601600314

[10] Hinman, A.R., Foege, W.H., de Quadros, C.A., Patriarca, P.A., Orenstein, W.A. and Brink, E.W. (1987) The Case for Global Eradication of Poliomyelitis. Bulletin of the World Health Organization, 65, 835-840.

[11] Hull, H.F. and Lee, J.W. (1996) Sabin, Salk or Sequential? Lancet, 347, 630. http://dx.doi.org/10.1016/S0140-6736(96)91194-0

[12] Gust, D.A., Strine, T.W., Maurice, E., Smith, P., Yusuf, H., Wilkinson, M., et al. (2004) Underimmunization among Children: Effect of Vaccine Safety Concerns on Immunization Status. Pediatrics, 114, e16-e22. http://dx.doi.org/10.1542/peds.114.1.e16

[13] Shui, I.M., Weintraub, E.S. and Gust, D.A. (2006) Parents Concerned about Vaccine Safety: Differences in Race/Ethnicity and Attitudes. American Journal of Preventive Medicine, 31, 244-251. http://dx.doi.org/10.1016/j.amepre.2006.04.006

[14] Gust, D., Brown, C., Sheedy, K., Hibbs, B., Weaver, D. and Nowak, G. (2005) Immunization Attitudes and Beliefs among Parents: Beyond a Dichotomous Perspective. American Journal of Health Behavior, 29, 81-92. http://dx.doi.org/10.5993/AJHB.29.1.7

[15] Gust, D.A., Darling, N., Kennedy, A. and Schwartz, B. (2008) Parents with Doubts about Vaccines: Which Vaccines and Reasons Why. Pediatrics, 122, 718-725. http://dx.doi.org/10.1542/peds.2007-0538

[16] Patel, M.M., Janssen, A.P., Tardif, R., Herring, M. and Parashar, U.D. (2007) A Qualitative Assessment of Factors Influencing Acceptance of New Rotavirus Vaccine among Health Care Provider and Consumers. BMC Pediatrics, 7, 32. http://dx.doi.org/10.1186/1471-2431-7-32

[17] Williams, S.E., Rothman, R.L., Offit, P.A., Schaffner, W., Sullivan, M. and Edwards, K.M. (2013) A Randomized Trial to Increase Acceptance of Childhood Vaccines by Vaccine-Hesitant Parents: A Pilot Study. Academic Pediatrics, 13, 475-480. http://dx.doi.org/10.1016/j.acap.2013.03.011

[18] Oyedeji, G.A. (1985) Socioeconomic and Cultural Background of Hospitalized Children in Ilesha. Nigerian Journal of Paediatrics, 12, 111-117.

[19] Tagbo, B.N., Ughasoro, M.D. and Esangbedo, D.O. (2014) Parental Acceptance of Inactivated Polio Vaccine in Southeast Nigeria: A Qualitative Cross-Sectional Interventional Study. Vaccine, 32, 6157-6162. http://dx.doi.org/10.1016/j.vaccine.2014.08.053

[20] Salsberry, P., Nickel, J. and Mitch, R. (1993) Why Aren’t Preschoolers Immunized? A Comparison of Parents’ and Providers' Perceptions of the Barriers to Immunizations. Journal of Community Health Nursing, 10, 213-224. http://dx.doi.org/10.1207/s15327655jchn1004 2

[21] Nichter, M. (1990) Vaccination in South Asia: False Expectations and Commanding Metaphors. In: Coreil, J., Ed., Anthropology and Primary Health Care, Westview Press, Oxford, 196-221.

[22] Expanded Programme on Immunization (1998) The Social Science and Immunization Research Project. Weekly Epidemiological Record, 73, 285-288.

[23] Wright Clayton, E., Hickson, G.B. and Miler, C.S. (1994) Parents’ Responses to Vaccine Information Pamphlets. Pediatrics, 93, 369-372.

[24] St-Armour, M., Guay, M., Parron, L., Clément, P., Baron, G., Petit, G. and Lemaire, J. (2006) Are Vaccination Information Leaflets Useful for Vaccinators and Parents? Vaccine, 24, 2491-2496.

[25] Salmon, D.A., Sotir, M.J., Pan, W.K., Berg, J.L., Omer, S.B., Stokley, S., et al. (2009) Parental Vaccine Refusal in Wisconsin: A Case-Control Study. WMJ, 108, 17-23.

[26] Lagarde, F. (2005) Summary of Public Opinion on Immunization in Canada. Public Health Agency of Canada, Ottawa, 19. 
Scientific Research Publishing (SCIRP) is one of the largest Open Access journal publishers. It is currently publishing more than 200 open access, online, peer-reviewed journals covering a wide range of academic disciplines. SCIRP serves the worldwide academic communities and contributes to the progress and application of science with its publication.

Other selected journals from SCIRP are listed as below. Submit your manuscript to us via either submit@scirp.org or Online Submission Portal.
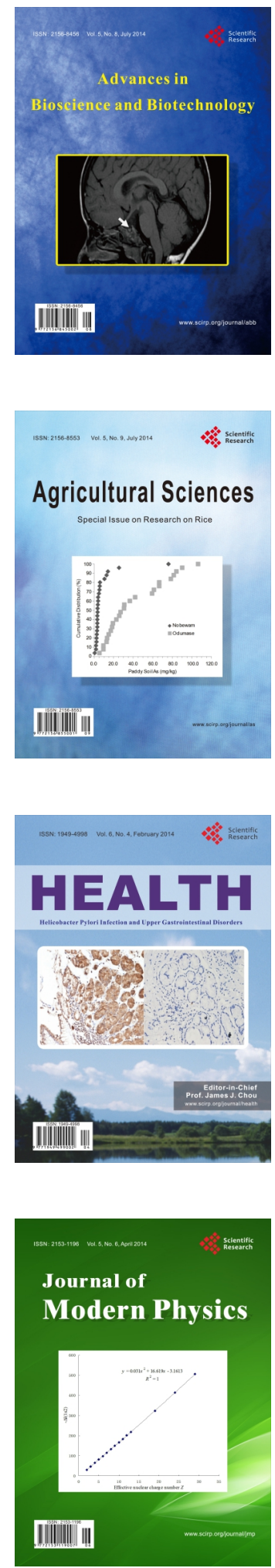
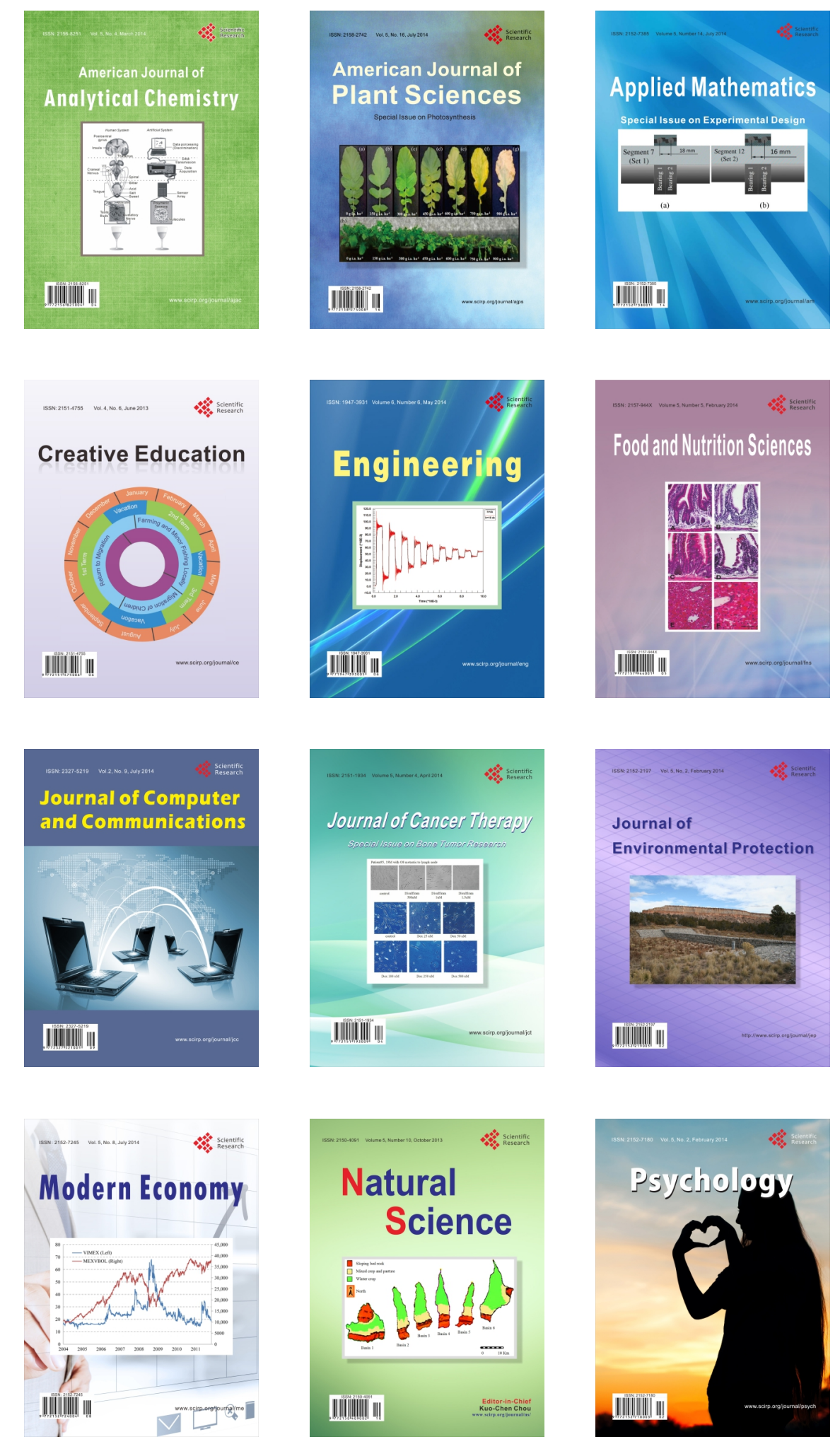